\title{
artículos
}

\section{Iconografía religiosa realizada por artistas andaluzas del siglo XIX}

\author{
Matilde Torres López \\ Investigadora vinculada a la UMA
}

RESUMEN

El presente artículo es y resultado de varios años de investigación sobre la docencia y el aprendizaje artístico de la mujer en Andalucía en el siglo XIX ${ }^{1}$, analizándola en su labor artística con la temática religiosa. Las copias de cuadros de grandes pintores se alternaban con las propias composiciones de algunas de ellas. Hoy existen pocas obras realizadas por mujeres pero resultan suficientes para apreciar por qué elegían este tema: bien porque habian adquirido un avanzado nivel de aprendizaje o por la propia devoción que muchas de las autoras profesaban en el ámbito religioso.

PALABRAS CLAVE: Arte/ Docencia/ Mujer/ Andalucía/ siglo XIX. century

Religious iconography realized by andalusian women artists s of the 19th

ABSTRACT

The present article is and result of several years of investigation on the teaching and the artistic learning of the woman in Andalusia in the 19th century, analyzing it in his artistic job with the religious subject matter. The copies of pictures of big painters they were alternating with the own compositions of some of them. Today few works realized by women exist but they turn out to be sufficient to estimate why they were choosing this topic: well because they had acquired an advanced level of learning or for the own devotion that many of the authoresses were practising in the religious area.

KEY WORDS: Art/ Teaching/ Woman/ Andalucía/ XIXth century.

\section{INTRODUCCIÓN}

El siglo XIX fue bastante convulsivo, con unas actuaciones transgresoras y rotundas para la historia de España, por supuesto para Andalucía, ya que fue cuando se comenzó el cambio desde el Antiguo al Nuevo Régimen. Las estructuras políticas, jurídicas, económicas, sociales y culturales que habían estado inamovibles durante siglos entraron en un constante proceso de crisis, debido al fenómeno bélico y sobre todo revolucionario, que fueron muy profundos. Fue el siglo del liberalismo, de la revolución industrial y de la burguesía, por lo que las consecuencias de todos esos factores afectaron al país ${ }^{2}$, aunque con matizaciones en las distintas provincias.

* TORRES LÓPEZ, Matilde: "Iconografía religiosa realizada por artístas andaluzas", en Boletín de Arte, $\mathrm{n}^{\circ}$ 3031, Departamento de Historia del Arte, Universidad de Málaga, 2009-2010, págs. 271-286. Fecha de recepción: Abril de 2009

1 TORRES LÓPEZ, Matilde. La mujer en la docencia y la práctica y artística en Andalucía durante el siglo XIX. Edit. SPICUM. Servicio de Publicaciones de la Universidad de Málaga. Málaga, 2008. Págs. 11-16.

2 BAHAMONDE, Ángel y MARTíNEZ, Jesús A. Historia de España siglo XIX. Ediciones Cátedra. Madrid, 2005. Págs. 13-20. 
Ante ese panorama también hay que mencionar que en Andalucía durante el siglo XIX existió una notable diferencia entre las provincias, particularmente en el aspecto económico, social y cultural, destacando algunos núcleos formado por las capitales costeras de Almería, Málaga, Granada y Cádiz. Sus características económicas y sobre todo comerciales, con la inclusión de una población foránea bastante extensa, abrió posibilidades y sobre todo un relativo cambio de mentalidad, para considerar necesaria la instrucción de la mujer en la actividad artística.

Otras ciudades como Córdoba, Sevilla y sobre todo Huelva y Jaén, donde las condiciones no fueron las óptimas en cuanto a esa sensibilización social, la idea de que la mujer pudiera tener un papel activo en el arte fue algo más paulatina durante este siglo. No obstante en la mayoría de las provincias, de forma más clara en el litoral mediterráneo, hubo un importante número de ciudadanos que apoyó las inquietudes de esas mujeres para adquirir conocimientos artísticos, encontrándose además artículos y tratados de esa centuria en los que sus autores cuestionaban la pésima instrucción que se daba a las jóvenes, además de aportar posibles soluciones para que tuvieran una mejor educación, incidiendo en la posible salida laboral.

Hay que destacar que la mayoría de las jóvenes que optaban por esta preparación, eran casi todas pertenecientes a la clase media de la sociedad, ya que eran ellas por conocimientos y posibilidades las que podían asistir a las clases o pagar a un profesor particular, pues la familia y el entorno les daba una base que les permitía recibir ese aprendizaje, aunque no debemos olvidar una realidad importante y es que en esa centuria en Andalucía había un elevado número de analfabetismo y concretamente la mujer se encontraba en el colectivo que mayores tasas tenía.

Hubo un importante número de pintoras, aunque no todas fueron artistas reconocidas por su labor, ni en su época, ni con posterioridad, e incluso de las conocidas tenemos poca información y casi nada de su obra, pues su trabajo difícilmente ha llegado hasta nuestros días. De muchas de ellas apenas conocemos datos, salvo las escuetas referencias en los catálogos de exposiciones en las que mostraron su trabajo o en las listas de alumnas de los distintos centros donde obtuvieron el aprendizaje de las técnicas artísticas.

La mayoría eran alumnas de las Escuelas correspondientes a las Academias de Bellas Artes y posteriormente de las Escuelas de Artes y Oficios; otras cursaban sus estudios en entidades privadas, como la Sociedad Económica de Amigos del País, el Ateneo o Liceo de sus respectivas ciudades, y también las había que aprendían de forma libre, recibiendo esta enseñanza específica en sus propios domicilios o en los talleres de renombrados pintores y docentes. Pero a todas ellas se las denominaba, independientemente de su nivel artístico, e incluso laboral, simplemente como "aficionadas", pues las que, por el reconocimiento de su labor artística, llegaron a ser nombradas académicas por la Academia de Bellas Artes de su localidad o por la Academia de Bellas Artes de San Fernando, tampoco fueron reconocidas en su trabajo, pensándose que casi todas copiaban -cosa muy normal en esa centuriay creaban por "pura afición". También encontramos frecuentemente que muchas de 
ellas, algunas con excelentes aptitudes para la creación artística, tuvieron que dejar su carrera cuando ya eran reconocidas, incluso fuera del ámbito local, a veces por la presión social, otras por obligaciones familiares -particularmente al contraer matrimonio-, no olvidando que les estaba permitido relativamente aprender y desarrollar sus conocimientos artísticos, pero siempre dentro de los límites, del círculo cerrado del hogar, como mucho de la familia y los amigos, pues mostrar su obra en exposiciones y eventos, sobre todo a nivel nacional, no estaba tan bien visto.

La mayor parte de estas mujeres llevaban varios años preparándose artísticamente, en particular las que estaban en las Escuelas de Bellas Artes y Escuelas de Artes y Oficios, por eso cuando presentaban obra a concursos y exposiciones, no era la primera vez que realizaban un trabajo, así que antes de mostrar, algunas de ellas ya tenían experiencia con los lápices, los pinceles o buriles, lo que nos lleva a pensar que debían tener más producción que las expuestas, sólo que no han llegado a nosotros.

\section{LA EDUCACIÓN ARTÍSTICA DE LA MUJER.}

La educación que recibía la mujer, ya desde su infancia, iba encaminada a hacer de ella una buena esposa y madre que ejerciera perfectamente su rol dentro del hogar; pues era el pilar fundamental de la familia, estructura básica de la estabilidad social del siglo XIX, e independientemente de la escala social a la que perteneciera. La enseñanza de la mujer en esa centuria, no estuvo exenta de problemas debido sobre todo a los altibajos políticos, pero vio una posibilidad de mejorar la situación a partir de la revolución de 1868, aunque los buenos propósitos apenas si se cumplieron, achacándose de ello a tres aspectos básicos como eran la mentalidad predominante, el tipo de trabajo que realizaban y sobre todo la poca preparación cultural que tenían ${ }^{3}$. En clases altas la educación iba marcada por un fuerte contenido espiritual y moral, más que intelectual, principios que se enseñarían en la propia casa, bien por la madre o por institutrices, dependiendo de la posibilidad económica; posteriormente se llevaría a la joven a colegios privados fuera del país, aunque poco a poco y con la creación de centros específicos para la enseñanza de la mujer en nuestra Comunidad, se quedaban más cerca de sus domicilios. Dicha educación consistía en saber un poco de lectura, escribir, bordar y coser, a veces algunas nociones de Geografía, Música y Dibujo, además de Francés que daba la nota al máximo de su preparación 4 .

\footnotetext{
3 ARIAS DE COSSíO, Ana María. "Mujeres que miran al cambio de siglo". Prototipos e imágenes de la mujer en los siglos XIX y XX. Atenea. Estudios de la mujer. QUILES PAZ, Amparo y SAURET GUERRERO, Teresa. (Coord.). Edit. Servicio de Publicaciones de la Universidad de Málaga. Málaga, 2002. Págs. 101-104. 4 RAMOS FRENDO, Eva Ma. "El modelo burgués femenino visto a través del arte". Actas del Congreso Luchas de género en la historia a través de la imagen. QUILES FAZ, Amparo y SAURET GUERRERO, Teresa. (Edit.). Tomo II. Edit. Servicio de Publicaciones. Centro de Ediciones de la Diputación Prov. de Málaga. (CEDMA). Málaga, 2002. Págs. 222-225.
} 
Centrándonos en la educación artística, vemos la dificultad de acceso que las jóvenes tenían para entrar a las academias, cuando estaban creadas, y si lo lograban, la deficiencia del plan de estudios que se les aplicaba, lo cual generó problemas en la formación artística de la mujer. Si bien, las clases de enseñanza artística destinada a ese colectivo se fueron instaurando poco a poco, tanto en las academias oficiales como en los centros privados, las asignaturas que se les impartía fueron limitadas, adaptándolas siempre a su género. Las primeras escuelas reconocidas oficialmente tenían el claro propósito de formar a las alumnas para la posterior inserción en las industrias artísticas. Otras muchas jóvenes optaron por diferentes vías o canales de aprendizaje e incluso decidiendo aprender por ellas mismas, con la ayuda de tratados y cartillas de dibujo 5 .

El comienzo del aprendizaje de las jóvenes, era la copia de objetos geométricos, composiciones que se iban dificultando según la experiencia adquirida. Tras el aprendizaje del dibujo y la composición, pasaban a utilizar la pintura y a realizar bodegones y cuadros de flores. Otro camino era las clases particulares; esa enseñanza la impartía mayoritariamente profesores que trabajaban en centros oficiales, pero también a nivel privado, bien en los domicilios de las jóvenes o en su propio taller6. Muchos de los maestros debieron ser autónomos, siendo la mayoría de las veces pintores no reconocidos.

Aunque en menor cantidad, también hubo mujeres profesoras que impartían la asignatura de Dibujo y otras la de Pintura. Esas profesoras daban clase a otras mujeres, a veces particulares, otras, en menor cantidad, en centros oficiales. Tanto ese tipo de enseñanza, como la venta de sus obras, era una labor que relativamente no estuvo mal vista en la sociedad, pudiéndose por tanto ganar la vida profesionalmente. Sin embargo hay que señalar que la docencia impartida por la mujer podía ser más deficiente debido a que su formación estuvo más limitada, tanto en la técnica como en la historia del Arte, arrastrándose la situación generación tras generación. Mientras la mujer siguió con ese tipo de instrucción artística, la mayoría de ellas no pudo crear determinadas composiciones, ni mostrarlas, menos aún sacarlas al mercado, quedando sus expectativas casi reducidas a la actividad industrial.

Por otra parte, las docentes enseñaban un tipo de arte denominado peyorativamente femenino, lo que evitaba complicaciones por una parte, aunque en el fondo sólo fuera lo que podían enseñar, bien porque estaba en los planes de estudios que debían seguir, bien porque era lo que a ellas les habían permitido aprender7 ${ }^{7}$. Muchas

5 FREIXA, Mireia. "Las mujeres artistas. Desde la Revolución francesa al fin de siglo". Historia del Arte y mujeres. Atenea. Estudios sobre la mujer. SAURET, Teresa. (Coord.). Universidad de Málaga. Málaga, 1996. Págs. 78-80.

6 POVEDANO MARRUGAT, Elisa. "La mujer española en la educación artística del siglo XIX: Academia, Escuela de Bellas Artes y Escuelas de Artes y Oficios". Actas del Congreso Luchas de género en la historia a través de la imagen. Tomo II. QUILES FAZ, Amparo y SAURET GUERRERO, Teresa (Edit.). Tomo I. Edit. Servicio de Publicaciones. Centro de Ediciones de la Diputación Prov. de Málaga. (CEDMA). Málaga, 2002. Pág. 52.

7 DE DIEGO, Estrella. La mujer y la pintura en la España del siglo XIX. Mujeres pintoras en Madrid: 1868- 
de ellas provenían de la actividad artística, situación que tuvieron que cambiar a la hora de contraer matrimonio, acomodándose por ello a un trabajo más íntimo o recogido como era la enseñanza. La mayoría pertenecía a familias de pintores, lo que les daba más prestigio o garantía para montar su propio taller de Dibujo o Pintura. De esas profesoras hay que decir que muchas contaron con un gran número de alumnas, incluso más que algunos profesores varones, pues como es lógico, en ese siglo y bajo su mentalidad, se veía mejor enviar a las hijas a formarse con otras mujeres.

\section{FORMACIÓN.}

Cuando hablamos de una "estética femenina", siempre hemos de tener en cuenta las circunstancias, las limitaciones que durante toda la historia ha tenido la mujer artista. El arte de las mujeres no se diferencia en lo básico al del hombre, pero sí en su aprendizaje, sus conocimientos artísticos, así como las propias experiencias personales, que por el hecho de ser mujer, le ha estado limitado a todos los niveles.

Llegados a ese punto, nos encontramos con un grave problema a la hora de entender el papel de la mujer artista durante el siglo XIX, que no sólo tenía dificultades para acceder a una educación completa, pues se ha excluido de la clase de Anatomía Pictórica, de la figura humana. De esa asignatura se excluía a la mujer no solamente en nuestras academias y escuelas, sino también, en el resto de Europa y América y en períodos anteriores, ya que esa clase se consideraba indecorosa y atentaba contra la moral de las jóvenes. No obstante, en toda representación artística de esa centuria, el dibujo del desnudo constituía la base para la preparación académica y posteriores composiciones, tanto pictóricas, como escultóricas ${ }^{8}$.

Esas asignaturas tabú para la mujer le han afectado en su creación artística durante toda la historia, pues que no pudiesen aprender dichas materias ya las descalificaba de antemano para hacer grandes composiciones, para entrar en las academias, para optar a becas y premios, quedando siempre atrás y limitándose a hacer lo que les dejaban: copias de los llamados temas "menores", según los esquemas academicistas y sobre todo durante el siglo $\mathrm{XIX}^{9}$.

La técnica utilizada por la mujer, en todos los tiempos, ha sido variada dependiendo sobre todo de la economía y de la posibilidad de poder utilizarlas. Hay que reconocer que independientemente de la preparación artística, le seguía el factor económico, intentando localizar lo más asequible a sus bolsillos para poder obtener los materiales, siempre dentro del campo de la pintura, aunque algunas de ellas, muy buenas profesionales tanto en la labor artística como en la docente, provenían

1910. Tomo II. Dpto. de Historia del Arte. Fac. de Geografía e Historia. Univ. Complutense de Madrid. Madrid, 1987. Pág. 482-484

8 AGUILERA, Emiliano M. El desnudo en el Arte. Edit. Joaquín Gil. Barcelona, 1932. Pág. 5.

9 DE DIEGO, Estrella. La mujer y la pintura del XIX español (Cuatrocientas olvidadas y algunas más). Edit. Ensayos de Arte Cátedra. Madrid, 1987. Págs. 191-197. 
de talleres de manufacturas donde pintaban decorando objetos varios, bien en madera, tela e incluso sobre marfil.

Las jóvenes comenzaban casi siempre, en su propio domicilio para pasar luego a las academias, en las que aprendían realizando composiciones a lápiz, a veces de dos o más colores, después trabajaban con el pastel, la acuarela que era la técnica más utilizada desde finales de la Edad Media y durante todo el XIX, ya que se consideraba respetable y propia para las mujeres, o directamente pasaban al óleo ${ }^{10}$, suponiendo que para trabajar con éste último, se debía tener un aprendizaje bastante bueno, así como unos conocimientos aceptables del material utilizado.

\section{ICONOGRAFÍA RELIGIOSA.}

Entre los temas iconográficos trabajados por la mujer, destaca el religioso, es más, éste se le permitía y potenciaba, pues no hay que olvidar que mediante la imagen, la Iglesia enviaba mensajes a sus fieles, de forma directa y efectiva, ya que la mayoría del pueblo no sabía leer, y mediante la iconografía de la Virgen -sobre todo-, de Jesucristo y la vida de los Santos, se daba a conocer la doctrina católica. La Iglesia utilizaba los programas iconográficos como propaganda, que sobre todo iba destinada a la propia mujer, ya que se ensalzaba la virginidad, la maternidad y la familia, por supuesto la virtud, y era ella la destinada de transmitir los cánones establecidos. Así las representaciones religiosas se realizaban de forma más íntima y familiar, para llegar a la sensibilidad y la emoción del espectador, destacando entre todo el plantel religioso, el de las imágenes de Santa Isabel de Hungría y Santa Isabel de Portugal ${ }^{11}$.

La temática religiosa tiene una larga trayectoria y afianzamiento, cuando hablamos de que era la mujer quien ejecutaba esas obras, desde la época Moderna hasta bien entrado el siglo XX. También se utilizaba como modelo educativo destinado al colectivo femenino, a las heroínas del Antiguo Testamento; no hay que olvidar que el papel de esas mujeres siempre era el de esposa y el de madre y dando ejemplo de moralidad, entre ellas destacan Judith, Débora, Esther y Abigail.

En los centros artísticos de Andalucía, las pintoras que tenían una experiencia considerable copiaban frecuentemente los cuadros religiosos de reconocidos maestros, a veces en pequeño tamaño, otras en grandes lienzos. La preferencia era por los reconocidos pintores del Barroco como Velázquez y Murillo, sobre todo el segundo quien fue mayoritariamente copiado, definiéndolo a finales de siglo como un

10 DE ULIERTE VÁZQUEZ, Luz. "El arte es género ambiguo. Consideraciones metodológicas acerca de la historia del arte y las mujeres". Historia del Arte y mujeres. Atenea. Estudios sobre la mujer. SAURET, Teresa. (Coord.). Universidad de Málaga. Málaga, 1996. Págs. 23-29.

11 CHERTA MANSÓ, Ma Ángeles. "La imagen religiosa femenina en la educación de las mujeres vista por las propias artistas del Siglo de Oro en España". Actas del Congreso Luchas de género en la Historia a través de la imagen. QUILES FAZ, Amparo y SAURET GUERRERO, Teresa. (Edit.). Tomo I. Edit. Servicio de Publicaciones. Centro de Ediciones de la Diputación Prov. de Málaga. (CEDMA). Málaga, 2001. Págs. 733-735. 
"pintor de señoritas"12.

Haciendo un recorrido por diversas provincias andaluzas, hay que decir que en Cádiz hay algunas de las escasas obras que han llegado hasta hoy, de buena calidad y realizadas por varias autoras que trabajaron esta temática.

Una de ellas es Josefa Campero quién mostró dos cuadros en la Exposición de Bellas Artes celebrada en 1840, promovida por la Academia de Bellas Artes de Cádiz, con los títulos de Un monje y a Nuestro Señor Jesucristo difunto, además de una copia de Poussin realizada a tinta china. También presentó otros trabajos en la exposición de 1841 celebrada en la misma ciudad.

Ana Gertrudis Urrutia y Garchitorena. Artista nacida en Cádiz en 1812, que falleció en 1850. Pintora y académica de mérito en la sección de Pintura histórica de la Academia de Bellas Artes gaditana en el año 1846, realizó notables copias al óleo que figuraron en diversas exposiciones públicas de la ciudad, destacando entre ellas San Jerónimo que se conserva en la Catedral de Cádiz.

Otra obra fue la titulada La resurrección de la carne, cuadro conocido por el Juicio, que figuró en la Exposición Nacional de 1846 y Santa Filomena, composición de gran valor pictórico que actualmente se encuentra en la Catedral gaditana.

Abencia Villa Lombera, participó en diversas exposiciones de Bellas Artes celebradas en la ciudad gaditana y a las que presentó diferentes trabajos, siendo muy elogiadas sus copias de San Antonio, Santa Clara y la Cabeza de un Apóstol.

N. Younger presentó dos obras a la Exposición Pública convocada por la Academia de Bellas Artes de Cádiz en agosto de 1854; uno de los lienzos representaba un Ecce-homo.

Susana de la Biesca, también alumna de la Escuela, presentó el lienzo titulado La Virgen de la Paloma en la Exposición Pública de 1856, muestra que fue promovida por la Academia de Bellas Artes gaditana.

Abencia de Viya, compañera de aula de las anteriores autoras presentó dos pinturas tituladas $D^{a}$ Blanca y San Antonio a la Exposición Pública de 1856, promovida por la Academia de Bellas Artes de Cádiz. Presentó un lienzo con la copia de Un Apóstol en la Exposición Pública de 1858, por el que le concedieron medalla de plata.

Ángeles Díaz Rocafull presentó en la Exposición de Cádiz celebrada en el año 1879, un lienzo al óleo de San Joaquín. Su hermana Pilar mostró en la misma Exposición un cuadro en el que representaba a San Vicente.

Emilia Enrile y Flores fue premiada por la Academia de Bellas Artes de Cádiz en la sección de Pintura. Discípula de la Escuela obtuvo en distintas ocasiones las felicitaciones de la prensa y el elogio de los especialistas. Al finalizar el curso académico de 1852-53 fue premiada con medalla de plata por la asignatura de Dibujo de Figura. La misma distinción la recibió al siguiente curso por la sección de Pintura.

12 gARcía fELgueRA, María de los Santos. La Fortuna de Murillo. Edit. Excma. Diputación Prov. de Sevilla. Sevilla, 1989. Pág. 251. Hay bastante información sobre las copias de Murillo realizadas por mujeres. Era también el predilecto de las mujeres de la familia real como la reina María Cristina, Isabel II y la reina madre, quienes habían realizado copias de Sagradas Familias y de Vírgenes del pintor sevillano. 
En la Exposición de 1856 presentó una copia al óleo de la Hermosa Judith, habiendo sido premiada con la medalla de plata en las Exposiciones de 1858 y 1862 por sus cuadros La Virgen de los Dolores, San Francisco y San Félix de Cantalicio, ésta última copia de Alonso Cano.

María del Pilar Escribano y Paul, también alumna de la Escuela de Bellas Artes de Cádiz presentó dos obras a la Exposición Pública de 1856, promovida por la Academia. Dichas obras eran las tituladas Esther y Asuero y un Retrato de Mignard. En 1861 contribuyó para la rifa de objetos artísticos, destinada a recaudar fondos y colocar un monumento en su ciudad natal al pintor Murillo. Las obras ofrecidas eran Una Dolorosa y Un Salvador.

Amalia García de Michelena presentó obra a la Exposición Pública celebrada en Cádiz en 1854, promovida por la Academia de Bellas Artes de la ciudad.

También llevó el lienzo titulado Jacob y Lia a la Exposición Pública organizada por la misma entidad el año 1856.

Alejandrina Gessler de Lacroix, conocida como Madame Anselma, fue una pintora nacida en Cádiz en 1831, hija de Alejandro Gessler, cónsul general de Rusia en España y de Aurora Shaw. Alejandrina aprendió en Cádiz sus primeras lecciones de Dibujo y de Pintura. En 1852 comenzó un viaje de estudios con sus padres a los museos de Madrid, Londres, París, Berlín y San Petesburgo. Finalizado el viaje en 1853, se instaló en París, trabajó en la capital con los pintores Gerome, Baunat, Chaplin y Lefevre, mostrando su primera obra en el Salón de 1863, titulada La Sagrada Familia, cuadro que estaba destinado al castillo de Montegut en Francia. A partir de entonces participó con bastante frecuencia en los salones de París, presentando retratos, cuadros de temática religiosa o costumbrista. Posteriormente se dedicó al género decorativo y a ese estilo pertenece su obra más importante, como la pintura de tres paños que decoraba el salón principal de su palacio de París y que hoy se encuentra en el salón de retratos del Museo de Bellas Artes de Cádiz. En esa composición se representaba La pintura, La tierra y Las cuatro estaciones.

Cuando volvió a Cádiz en el año 1871, se dedicó a pintar temas relacionados con el costumbrismo español, como escenas de Carnaval, Semana Santa y Corpus. Viajó a Marruecos y de allí regresó a París. La Academia de Bellas Artes de Cádiz la nombró académica supernumeraria en 1872. Cinco años después de haber sido nombrada académica, Alejandrina Gessler presentó un pequeño lienzo a la Exposición de Bellas Artes, organizada por la Academia gaditana, cuyo título es La Adoración de la Cruz, por dicha obra fue premiada con la medalla de oro ${ }^{13}$.

Tras una gran labor, reconocida y premiada por sus contemporáneos, esta artista fue nombrada Académica Correspondiente en París, por la Real Academia de Bellas Artes de San Fernando.

13 MARTÍNEZ díAZ, Noemí y L.F. CAO, Marian. Pintando el mundo: Artistas latinoamericanas y españolas. Cuadernos inacabados, $n^{\circ} 37$. Edit. Instituto de la Mujer y Ministerio de Trabajo y Asuntos Sociales. Madrid, 2000. Pág. 177. 
En 1891, le fue encargada la pintura del techo del Ateneo de Madrid, que es una de sus mejores obras, nombrada por ello socia de honor de la entidad. Esta pintora publicó diversos trabajos y un libro titulado Recuerdos de Cádiz y de Puerto Real. Al morir, en el año 1907, legó al Museo de Cádiz el techo que pintó para su palacio: el telón boceto -de grandes dimensiones- para el teatro de Cádiz y el cuadro La adoración de la cruz, entre otras obras. Este cuadro se puede contemplar en el Museo Provincial de Cádiz [1].

Carolina Delgado, alumna de la Escuela de Bellas Artes presentó una

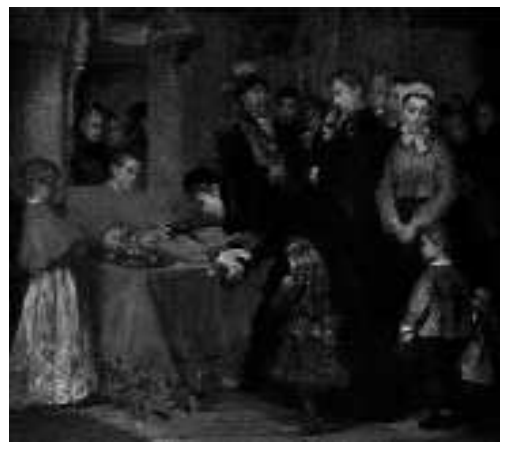

1. La adoración de la Cruz. ALEJANDRINA GESSLER SHAW. copia al óleo en la Exposición Pública promovida por la Academia de Bellas Artes gaditana. Fue premiada con medalla de plata en la Exposición de Cádiz de 1862, por un cuadro representando a San Sebastián.

Enriqueta Hidalgo, pintora y discípula de la Escuela de Bellas Artes de Cádiz, fue premiada mientras cursaba estudios. En la Exposición Provincial del año 1862, celebrada en la ciudad presentó un cuadro titulado La Concepción, por cuyo trabajo recibió una mención honorífica.

Victoria Martín Barrie del Campo nacida en Cádiz en $1784^{14}$. Pintora y académica supernumeraria de la Academia de Bellas Artes de su ciudad natal.

En las diferentes exposiciones públicas celebradas en Cádiz y en otras capitales andaluzas, desde 1840 a 1885, presentó numerosos lienzos -copias-, retratos y cuadros de composición, entre los trabajos deben mencionarse como más notables: Un nacimiento, Susana en el baño, Dance tocando el arpa, La Magdalena y Cupido niño con un jilguero.

En la nueva Catedral de Cádiz se conserva de esta pintora un San Lorenzo, que está en la capilla de las Reliquias, así como una Dolorosa [2]. Fue una de las responsables de la influencia del academicismo gaditano, en la pintura que se hizo en Málaga en la primera mitad del siglo.

Expositora asidua en la Academia de Cádiz desde 1840, aparece su nombre por primera vez en Málaga en 1843, cuando fue nombrada socia de mérito del Liceo Artístico, además de ejercer la docencia.

En la Exposición de 1845, realizada por esa entidad, expuso los cuadros titulados Sagrada Familia, Susana en el baño y David calmando las iras de Saúl. El

\footnotetext{
14 B.M.C. (Biblioteca Municipal de Cádiz). Fondos impresos de la Academia Provincial de Bellas Artes. Real Decreto dando una nueva organización a las Academias y Estudios de Bellas Artes. Imprenta, Librería y Litografía de la Revista Médica de Cádiz. Cádiz, 1850. Pág. 5.
} 


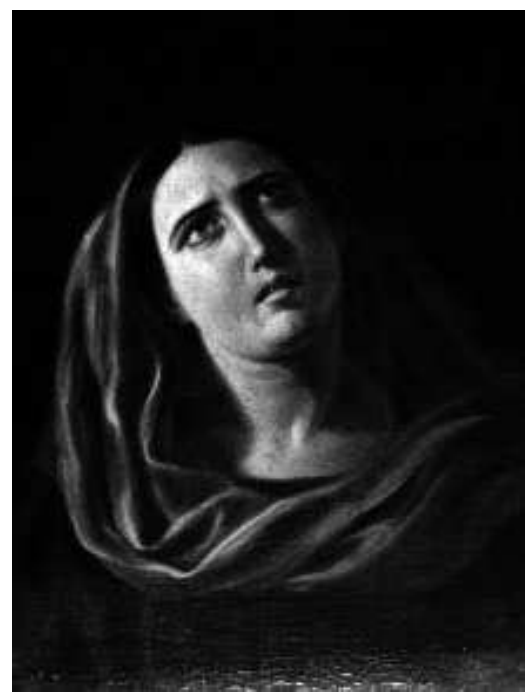

2. Dolorosa. VICTORIA MARTÍN.

secretario del Liceo elogió su forma de trabajar e invitaba a los pintores locales a seguir su modelo, fue esa una recomendación muy seguida, sobre todo por los pintores de temática religiosa. En el mismo catálogo de la Exposición se alude a su participación en otras exposiciones locales.

En 1847 se le nombró académica de mérito de la Nacional de Santa Cristina de Cádiz, hasta el año 1849 en que se extinguió, y en 1853 fue nombrada supervisora de la Provincial de Bellas Artes de Cádiz. Murió en 1869. En su ciudad se conservan varias obras realizadas por ella.

La escultora María del Carmen Ponce de León, en las Exposiciones de Bellas Artes celebradas en 1858 y 1862, en Jerez de la Frontera, obtuvo respectivamente medallas de bronce y de plata por su escultura titulada Safo, en yeso y un grupo escultórico de las Santas Justa y Rufina.

Manuela Muñóz de Cacho llevó un cuadro titulado La Sentencia de Jesús a la Exposición Pública organizada por la Academia de Bellas Artes gaditana, en 1860.

A la Exposición Provincial de Cádiz del año 1862, presentó el cuadro de La Virgen y Santa Ana por el que obtuvo medalla de plata.

Antonia Oviedo, pintora gaditana que en la Exposición celebrada en Cádiz el año 1879, presentó varios lienzos titulados Ecce Homo, La cena y Un coro de frailes. Fue premiada con medalla de bronce.

Angelina Paredes Ramírez, nacida en Cádiz y discípula de la Clase de Señoritas de la Escuela de Bellas Artes. Obtuvo un accésit en la sección de Pintura, en la Exposición Provincial que se celebró en la ciudad el año 1879. Realizó un Ecce Homo [3] al óleo que obtuvo el primer premio de la Exposición de Bellas Artes de 
3. Ecce Homo. ANGELINA PAREDES RAMÍREZ.

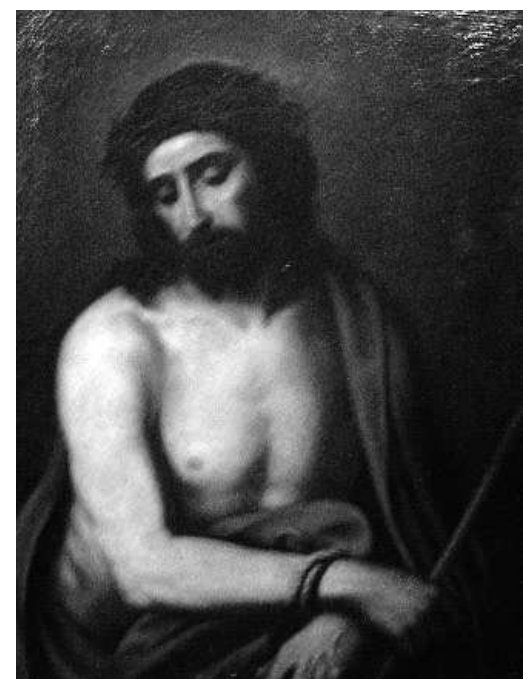

Cádiz celebrada en $1887^{15}$.

Matilde Pelufo, pintora gaditana que llevó obra a la sección de Pintura en la Exposición Pública, promovida por la Academia de Bellas Artes de Cádiz en 1854. También participó en la Exposición de Cádiz celebrada el año 1879, a la que presentó un lienzo titulado La Magdalena.

Enriqueta Rocafull, pintora que residía en Jerez de la Frontera. En el año 1879 concurrió a la Exposición Provincial de Cádiz llevando tres cuadros originales titulados La Magdalena, La Concepción y Lección de música en un colegio religioso. Por la última composición recibió medalla de bronce.

Dolores Rubio de Zurita fue alumna de la Escuela presentó obra a la Exposición Pública celebrada en la Academia de Bellas Artes de Cádiz en 1854. En la Exposición celebrada en la misma ciudad en el año 1879, presentó tres lienzos titulados Santa Teresa, El Divino Pastory Un Apóstol. Fue premiada con medalla de plata.

Ana Bayo presentó en la Exposición de Cádiz de 1879, un cuadro de San Pedro realizado al óleo, copia de Ribera, y por el que obtuvo una mención honorífica.

Pintora y escultora era Julia García que presentó varias de sus obras a la Exposición de Cádiz del año 1879. Fue premiada con mención honorífica por un lienzo ejecutado con la imagen de Santa Cecilia.

En Granada también hubo un importante grupo de mujeres que pintaban

15 A.E.B.A.C. (Archivo de la Escuela de Bellas Artes de Cádiz). Libro de Actas de 1881 a 1891. Estudios Libres de Señoritas-Lista de examinadas. Pág. 37. Este cuadro se encuentra actualmente en el museo $L a$ Casa del Ángel, de Ángel Garó, en Málaga, cuyo propietario es familiar de esta autora y al que le agradecemos el permiso para fotografiar el lienzo. 
temas religiosos, entre ellas Marina Aguilera quién presentó una copia de Ecce Homo a la Exposición de Pintura de 1898 organizada por el periódico El Defensor Granadino, en su Salón de Bellas Artes.

Carmen Balluertas realizó un cuadro titulado Virgen del Carmen, por el que se le concedió el título de socia de mérito, en la Sociedad Económica de Amigos del País de Granada en el año 1862.

Clementina Careaga participó en la Exposición de Bellas Artes de 1857 organizada por la Real Sociedad Económica de Amigos del País de Granada; presentó dos cuadros de Apóstoles.

Josefa Dávila, condesa de Catres, presentó dos copias en la sección de dibujos a lápiz, de la Exposición de Bellas Artes de 1849 organizada por el Liceo Artístico y Literario de Granada. A la Exposición de Bellas Artes de 1857 organizada por la Sociedad Económica de granadina, presentó un cuadro titulado Adoración.

María del Carmen Enríquez y Ferrer. Hija de Francisco Enríquez García y hermana del notable arquitecto y también pintor Francisco Enríquez Ferrer, estudió Dibujo y Pintura bajo la dirección de su padre, director de la Academia de Bellas Artes de Granada. Presentó en la inauguración del Liceo granadino, el 18 de noviembre de 1839, un cuadro al óleo titulado Una Sibila. A la convocada en noviembre de 1841, presentó un cuadro titulado Querubín.

Su hermana Soledad, igual que ella aprendió de su padre las técnicas artísticas $^{16}$. La Sociedad Económica de Amigos del País granadina, le hizo entrega de una carta de aprecio en el año 1835, a partir de la cual viajó a Madrid para perfeccionarse en la pintura, realizando copias de cuadros de artistas célebres del Museo del Prado.

Llevó a la inauguración del Liceo en 1839, presentó varias obras entre la que estaba la titulada Una Virgen. En su ciudad natal pintó los Retratos de varios arzobispos ${ }^{17}$.

El 16 de septiembre de 1856 fue nombrada profesora ayudante de la clase de Dibujo para señoritas de la Sociedad Económica de Amigos del País de Granada.

Alrededor de 1858 el matrimonio compuesto por Miguel Fernández-Cortacero Oliver y Ascensión Hernández, le encargaron para la capilla del Sagrado Corazón de la Iglesia de Alhendín -de la cual eran fundadores-, un programa iconológico del que hay siete cuadros, compuesto por un Sagrado Corazón de Jesús, San Diego de Alcalá, Santa Inés [4], San Patricio, San Miguel Arcángel, la Ascensión del Señor y San Antonio de Padua.

Dolores Figueras presentó a la Exposición de Bellas Artes de 1857, un lienzo titulado Jesús profanado por un judío.

A María García se le concedió el título de socia de mérito en 1862, al presentar dos cuadros a la exposición realizada por la Sociedad Económica de Amigos del País en Granada, uno de ellos era la imagen de una Virgen.

16 CAPARRÓS MASEGOSA, Lola. Artes plásticas en la prensa granadina del siglo XIX. Edit. Universidad de Granada. Arte y Arqueóloga. Biblioteca de Humanidades. Granada, 2001. Págs. 89-90.

17 MOLINA VALERO, José. La iglesia de Alhendín. Historia y Arte. Imp. Miguel León. Alhendín. Granada, 2000. Págs. 131-141. 
Emilia Gerona presentó un lienzo de Cristo en el huerto, en la exposición realizada en 1862 por la Sociedad Económica de Amigos del País de Granada, concediéndosele el título de socia de mérito. Su hermana Eulalia mostró obra en la Exposición de Bellas Artes de 1857 organizada por la Real Sociedad de Granada a la que presentó un lienzo en el que representaba a San Marcos.

Josefa Gumucio y Grinda. Pintora natural de Granada y discípula del pintor Francisco Mendoza. En las Exposiciones de la Academia de San Fernando de Madrid de los años 1848 y 1854, y de la General de Bellas Artes de 1856, expuso varias copias y retratos, además de la composición titulada Aparición de la Virgen a Jaime I de Aragón.

Dolores Jiménez Herrera y Lantoni residente en Granada en 1883. Realizó diversas

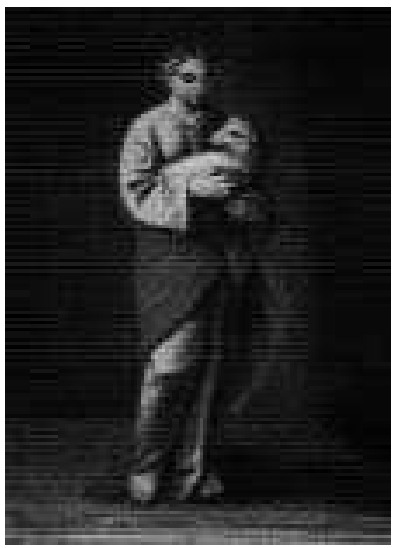

4. Santa Inés. SOLEDAD ENRÍQUEZ.

copias al óleo tituladas Un Crucifijo, La Dolorosa, San Juan y La Magdalena, además de un cuadro El martirio de Fray Ginés López Yánez de Quesada para la iglesia del pueblo de Mula, en Murcia.

Carmen Laín presentó varias copias pequeñas de Tiziano y Veronés, una de ellas titulada La Adoración, a la Exposición de Bellas Artes de 1857.

A Francisca Javiera Montealegre se le concedió mención honorífica en 1866, por una copia al óleo de San Antonio, presentada en la Sociedad Económica de Amigos del País en Granada.

Aurelia Navarro Moreno. Pintora nacida en Granada en 1882. Se formó artísticamente con los maestros granadinos Larrocha y Muñoz Lucena. Fue pensionada por la Diputación Provincial granadina, en cuyos fondos artísticos hay actualmente un cuadro suyo titulado Desnudo femenino, obra por la que obtuvo una medalla de bronce en la Exposición Nacional de $1908^{18}$.

Concurrió a la Exposición Nacional de Bellas Artes de 1904, donde le fue concedida una mención honorífica por su cuadro Sueño tranquilo, y a las de 1906 y 1908, en las que consiguió sendas medallas de bronce. Tomó parte en la Exposición de caricaturas y tarjetas postales organizada por el Centro Artístico y Literario de Granada en 1908 y en la colectiva de la misma entidad en 1916. Debido a la presión familiar ante el éxito de sus obras en las exposiciones, decidió profesar de monja en las Adoratrices en 1923 y desde esa fecha sólo realizó algunos trabajos pictóricos para su Orden ${ }^{19}$.

18 COLL, Isabel. Diccionario de mujeres pintoras en la España del XIX. Edit. Centauro Groc. Barcelona, 2001. Pág. 149.

19 RODRÍGUEZ TITOS, Juan. Mujeres de Granada. Edit. Excma. Diputación Prov. de Granada. Granada, 1998. Pág. 95. 
A Aurora Valenciano de Reyes se le concedió el título de socia de mérito por presentar en 1866, una copia al óleo de Herodías con la cabeza del Bautista, en los trabajos presentados en la Sociedad Económica de Amigos del País de Granada.

En Málaga, la tradición de mujeres pintoras estaba bastante arraigada en esa centuria, formándose un grupo de señoras y señoritas de alta y media clase social, destacando que en esta ciudad aunque hubo un importante grupo de pintoras que ejecutaban temas religiosos 20 , mayoritariamente y sobre todo las alumnas de la Clase de Señoritas de la Escuela de Bellas Artes, perteneciente a la Academia de Bellas Artes de San Telmo, otras muchas pintaban cuadros de paisajes, marinas y flores. Una de ellas fue Concepción Cuadra, de esta pintora de temática religiosa se conocen dos cuadros que están en la Catedral. En la antesacristía de la Catedral de Málaga hay un lienzo en el que representa a Santa Úrsula. Recibió medalla de plata en la Exposición de 1862 y en la celebrada de 1872 en Málaga, mostró dos cuadros titulados Una Virgen y San Francisco de Asís.

Trinidad Custodio de Pro estuvo dedicada especialmente a la temática del retrato, aunque no olvidó la religiosa. En el año 1883 realizó una copia al óleo de un cuadro de La Santísima Trinidad, trabajo que le encargó el obispo de la diócesis malagueña.

Margarita Gravier como sus hermanas Josefina y Joaquina, fue una de las primeras socias de mérito del Liceo malagueño. En 1845 también participó en la Exposición del Liceo mostrando un trabajo realizado con un lápiz al difumino que representaba a Judit y Holofernes ${ }^{21}$.

De las tres hermanas parece ser que fue Joaquina la que mayor aptitud y dedicación tuvo para la pintura. Presentó a la Exposición de 1845 El juicio de Salomón. Se conservan de ella dos copias de Vírgenes de Murillo: la que está en la Catedral titulada Virgen con el Niño y la del Museo Diocesano también titulada Virgen con el Niño22.

Josefa Milla pintora que al inaugurarse el Liceo de Málaga en 1843 fue nombrada socia de mérito por la sección de Bellas Artes, aunque en las exposiciones de esos años no aparezca en Málaga obras firmadas por ella. Exponía en certámenes locales y regionales de la década de los años 40 del siglo XIX, siempre con temas religiosos; ese mismo año presentó al Liceo de Granada un cuadro de San Pablo al óleo, original, y varias copias de Santos, entre ellas una en la que representaba a San Bruno ${ }^{23}$.

Un pintora destacable dentro de la temática religiosa fue Rafaela Roose. Perteneciente a una prestigiosa familia de burgueses malagueños, a la que se integró mediante el matrimonio. Dedicada a un tipo de arte muy académico y tradicionalista, representa la permanencia del murillismo en Málaga hasta 1880, fecha en la

20 TORRES LÓPEZ, Matilde. Pintoras malagueñas de temática religiosa en el siglo XXI. Ruta Cofrade 2009. Imp. Gráficas Digarza S.L.. Málaga. 2009. Págs. 48-50.

21 MUÑÓZ MARTíN, Manuel. Familias malagueñas del siglo XIX. Raíces, troncos, ramas... Tomo II. Edit. Real Academia de Bellas Artes de San Telmo. Málaga, 2006. Págs. 1120-1121.

22 RAMOS FRENDO, Eva María. El coleccionismo decimonónico malagueño. Edit. Dpto. de Historia del Arte. Universidad de Málaga. Málaga, 2002. Págs.142-143.

23 SAURET GUERRERO, Teresa. El siglo XIX en la pintura malagueña. Edit. Universidad de Málaga. Málaga, 1987. Pág. 703. 

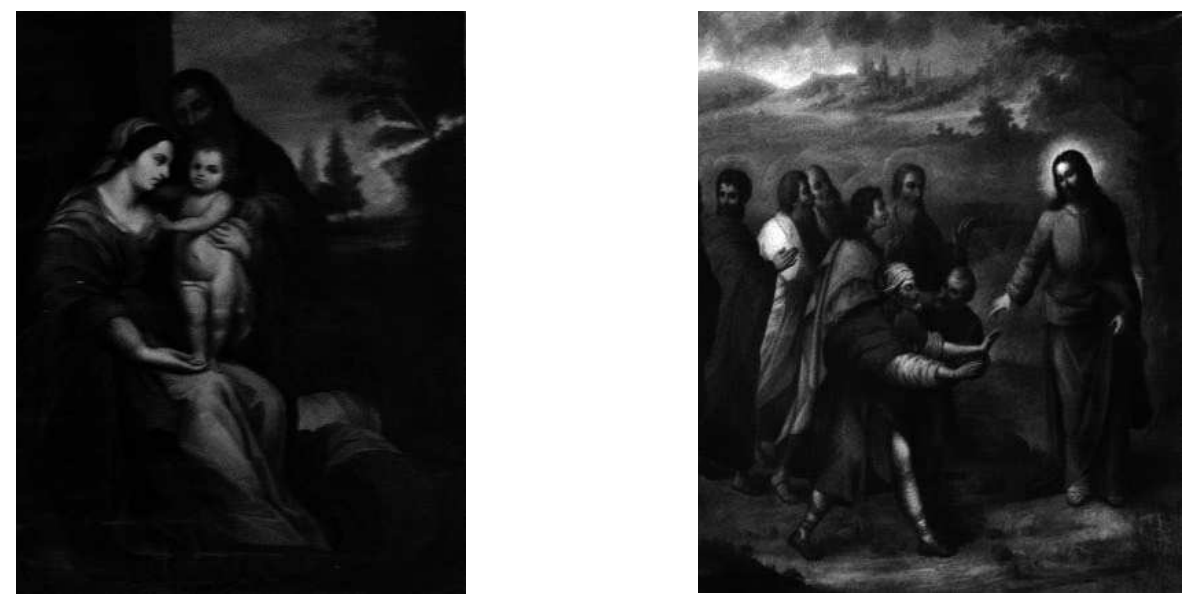

\section{Sagrada Familia. RAFAELA ROOSE.} 6. El ciego de Jericó. RAFAELA ROOSE.

que terminó su última obra conocida. Hay un conjunto de lienzos, inicialmente realizados para decorar la capilla del Pilar de la Catedral de Málaga. A la muerte de su esposo hizo una serie de cuadros como La adoración de los pastores -copia de Murillo-, El Calvario y La curación del ciego de Jericó, en la que la devoción se unía al recuerdo y, casi con carácter de exvoto por las dedicatorias. Las obras expuestas que están en el acceso al Patio de los Naranjos son Santa Lucía y la Aparición de la Virgen del Carmen a los fundadores de la Orden, ambas fechadas en 1862; en la antesacristía están La Virgen de la Antigua -copia del siglo XVIII- San Diego de Alcalá y un San Juan de Dios; en la capilla del Cristo del Amparo se encuentran un Descendimiento y un Calvario; situado en la capilla del Pilar hay un San Francisco y en la capilla de Santa Bárbara se encuentran la Adoración de los pastores, una Sagrada Familia y el Ciego de Jericó, todas fechas en el siglo XIX24 [5 y 6].

En Sevilla dentro del grupo de mujeres que trabajaban mayoritariamente la temática religiosa estaba Cipriana Álvarez Durán Machado, a quien se le concedió mención honorífica en la Exposición de Sevilla, celebrada en 1858. También participó en la Exposición de Bellas Artes de la misma ciudad celebrada el año 1868, a la que llevó dos obras tituladas Virgen -copiada del original de Murillo- y El Padre Eterno, copia de Pacheco. Por su parte la pintora Amparo Belloc residente en Sevilla en el año 1868, presentó obra a la misma exposición en la que mostró tres lienzos, uno de ellos titulado Santa Teresa.

24 SAURET GUERRERO, Teresa. La catedral de Málaga. Edit. Servicio de Publicaciones de la Diputación Prov. de Málaga. (CEDMA). Málaga, 2003. 
María Pastora Escudero, pintora que presentó en la Exposición de Sevilla de 1858 un cuadro realizado al óleo, por el que recibió una mención honorífica. En la Exposición celebrada en la ciudad el año 1868, llevó varias obras tituladas El casamiento de Rebeca, La Virgen de la Silla, El Descendimiento y Judith presentando al pueblo la cabeza de Holofernes.

María de los Dolores Gutiérrez recibió una mención honorífica en la Exposición de Bellas Artes de Sevilla celebrada en 1858, por un cuadro realizado al óleo. En el año 1861 realizó la obra titulada Los desposorios, que donó para la rifa con motivo del levantamiento de una escultura a Murillo en su ciudad. En esa misma época se sabe que también pintó en la población levantina de Denia.

Filomena Hermoso presentó en la Exposición celebrada en Sevilla el año 1868, una copia al óleo que representaba a San Pedro en oración.

Victoria Moreno fue premiada en la Exposición celebrada en Sevilla en 1842, por presentar un cuadro al óleo, copia de un original de Una Sacra Familia.

La pintora Genoveva Rothenflué presentó en la Exposición celebrada en Sevilla el año 1868, varias copias de cuadros de temas religiosos como la de San José, Santa Teresa, El Salvador y San Juan y La conversión de San Agustín. Del mismo año y en la misma Exposición Luisa Sierra y Gato mostró varias copias realizadas al óleo entre las que estaban las tituladas La Cruz del Campo y La Virgen del Rosario.

De la pintora sevillana Juana Valdivieso de Adriaensens, los Duques de Montpensier tenían en su colección particular el cuadro titulado Santas Justa y Rufina.

Jaén también contó con algunas pintoras dedicadas a esta temática señalando entre ellas a Francisca Aguilera Roldán, reconocida por sus copias, especialmente de las obras de Murillo. En la Exposición de Bellas Artes de Jaén celebrada en 1876, presentó un lienzo con San Francisco, copia de Alonso Cano, Santa Rita, del mismo autor y una Virgen, copia de Maella; también presentó Las hijas de Loth y La Magdalena, copias de Murillo.

Enriqueta Boristow residente en Linares, participó con varias obras en la Exposición Provincial de Jaén celebrada el año 1878, entre ellas se encontraba el liento titulado La Virgen. Josefa Elisa Orozco de Falache participó en la misma muestra a la que llevó varios cuadros titulados La Samaritana, La Virgen del Consuelo y La Virgen de la Misericordia25.

Puede que haya otras pintoras que trabajaron esta temática en el resto de las provincias andaluzas, pero no se han podido encontrar ya que muchas de ellas posiblemente se encuentren en colecciones particulares y aún no se han localizado.

25 OSSORIO BERNAL, M. Galería biográfica de artistas españoles del siglo XIX. Ediciones Giner. Madrid, 1975. Pág. 99. 